University of Nebraska - Lincoln

DigitalCommons@University of Nebraska - Lincoln

\title{
Validating sample preservation techniques and holding times for the approved compliance monitoring methods for haloacetic acids under the US EPA's stage 1 D/DBP rule
}

\author{
Barry V. Pepich \\ Shaw Environmental, Inc., pepich.barry@epa.gov \\ Mark M. Domino \\ Shaw Environmental, Inc. \\ Teri A. Dattilio \\ Shaw Environmental, Inc. \\ Patricia S. Fair \\ U.S. EPA \\ David J. Munch \\ U.S. EPA
}

Follow this and additional works at: https://digitalcommons.unl.edu/usepapapers

Pepich, Barry V.; Domino, Mark M.; Dattilio, Teri A.; Fair, Patricia S.; and Munch, David J., "Validating sample preservation techniques and holding times for the approved compliance monitoring methods for haloacetic acids under the US EPA's stage 1 D/DBP rule" (2004). U.S. Environmental Protection Agency Papers. 175.

https://digitalcommons.unl.edu/usepapapers/175

This Article is brought to you for free and open access by the U.S. Environmental Protection Agency at DigitalCommons@University of Nebraska - Lincoln. It has been accepted for inclusion in U.S. Environmental Protection Agency Papers by an authorized administrator of DigitalCommons@University of Nebraska - Lincoln. 


\title{
Validating sample preservation techniques and holding times for the approved compliance monitoring methods for haloacetic acids under the US EPA's stage 1 D/DBP rule
}

\author{
Barry V. Pepich ${ }^{\mathrm{a}, *}$, Mark M. Domino ${ }^{\mathrm{a}}$, Teri A. Dattilio ${ }^{\mathrm{a}}$, \\ Patricia S. Fair ${ }^{\mathrm{b}}$, David J. Munch ${ }^{\mathrm{b}}$ \\ ${ }^{a}$ Shaw Environmental, Inc., 26 W. Martin Luther King Drive, Cincinnati, OH 45219, USA \\ ${ }^{\mathrm{b}}$ US EPA, Office of Ground Water and Drinking Water Technical Support Center, 26 W. Martin Luther King Drive, Cincinnati, \\ OH 45268, USA
}

Received 18 September 2002; received in revised form 9 September 2003; accepted 19 September 2003

\begin{abstract}
Haloacetic acids (HAAs), which are formed during the disinfection of drinking waters with chlorine, are regulated by the US Environmental Protection Agency (EPA) under the Stage 1 Disinfectant/Disinfection Byproducts (D/DBP) Rule. Recently, three studies have been reported indicating that low concentrations of HAAs can also be formed during disinfection with chloramines. Methods currently approved for compliance monitoring under the Stage 1 Rule arrest the chlorine-mediated formation of HAAs by adding ammonium chloride, which forms chloramines. Studies were undertaken using an in-process water that favored the formation of HAAs with moderate total organic carbon concentration and high levels of chlorine to investigate the potential formation of HAAs under sample storage conditions. The ammonium chloride-quenched sample did form a small amount of HAAs, but total formation over a period equal to the 14-day sample storage time was less than $2 \mu \mathrm{g} / \mathrm{l}$, whereas the unquenched samples increased $41 \mu \mathrm{g} / 1$ during the same period. Pour plate studies indicated that chlorinated drinking waters quenched with ammonium chloride are protected from microbial growth, which is an important additional advantage to this preservation scheme. The presence of a combined chlorine residual should prevent microbial degradation of HAAs in samples. These studies support the preservation protocols and the sample storage times promulgated for compliance monitoring under the Stage 1 D/DBP Rule.
\end{abstract}

(C) 2003 Elsevier Ltd. All rights reserved.

Keywords: Disinfection byproducts; Haloacetic acids; Chloramines

\section{Introduction}

Halogenated organic compounds are formed during the disinfection of drinking water by the interaction of hypochlorous acid (or hypochlorite) with naturally occurring organic matter and bromide ion, if present. This reaction proceeds until either the reactive natural organic matter or the hypochlorous acid is consumed.

\footnotetext{
*Corresponding author. Tel.: +1-513-569-7439; fax: +1513-569-7837.

E-mail address: pepich.barry@epa.gov (B.V. Pepich).
}

Trihalomethanes (THMs) and haloacetic acids (HAAs) are two families of halogenated disinfection by-products (DBPs) that have been the source of numerous investigations. Because some of these compounds like dichloroacetic acid are classified as probable human carcinogens [1], they are regulated by the US Environmental Protection Agency (EPA) under the Stage 1 Disinfectant/Disinfection Byproducts (D/DBP) Rule [2].

Residual disinfectants are typically added to finished drinking waters prior to their entry into the distribution system to prevent the growth of microorganisms and ensure water quality. Waters with available natural 
organic matter and residual levels of disinfectants have the potential to continue forming disinfection byproducts during distribution. In order to ensure that analytical results reflect the HAA concentration at the time and point of sample collection, the three analytical methods approved for compliance monitoring of HAAs employ a chlorine quenching reagent to halt continued formation of HAAs [3-5].

The preservation of HAAs from chemical and microbiological degradation is clearly an important consideration for drinking water methods. Chlorine quenching reagents typically used in EPA drinking water methods are either reducing agents like sodium sulfite, sodium thiosulfate and ascorbic acid or amines that sequester the free chlorine through an equilibriumbased process like ammonium chloride or tris(hydroxymethyl)aminomethane [6,7]. Sodium sulfite has been shown to degrade at least one HAA under sample storage conditions [8]. This removed reducing agents from consideration as potential chlorine quenching reagents in the EPA methods for HAAs. Some HAAs are also subject to microbial degradation over short periods of time in the absence of appropriate levels of disinfectants [9-11]. In 1994, the Newport News Waterworks reported that the HAA levels they obtained for samples collected at locations with maximum residence times in their distribution system were lower than those sampled at intermediate locations [9]. As other plants started reporting similar observations, the authors of the original work identified two common characteristics in these plants: (i) the waters had low free chlorine residuals; and (ii) heterotrophic plate counts were high [10]. Additional work concluded that bacterial degradation of HAAs was possible during short periods of time under proper conditions $[10,11]$. The need to carefully preserve HAA samples was addressed in the currently approved HAA methods by using the chlorine quenching reagent, ammonium chloride. Since chloramines, which are also disinfectants, are formed by the interaction of hypochlorite with ammonium chloride, it was postulated that waters containing free available chlorine should be preserved from microbial degradation by the chloramines formed when ammonium chloride is added. This postulate, however, was not investigated during the development of the previous methods.

Recently, a number of investigators have reported the formation of HAAs from disinfection with chloramines $[12,13]$ or ozone followed by chloramines [14]. Diehl et al. studied the formation of six of the HAAs (excluding the brominated trihaloacetic acids) over two days at $22^{\circ} \mathrm{C}$ in three natural waters of varying TOC concentrations. They reported a median total concentration of $33.5 \mu \mathrm{g} / 1$ in high TOC water [12]. Cowman and Singer [13] investigated the formation of HAAs during chloramination of a synthetic water with a TOC of $4 \mathrm{mg} / 1$ at room temperature for $24 \mathrm{~h}$. They reported the formation of dichloroacetic acid (DCAA) at concentrations up to $9 \mu \mathrm{g} / \mathrm{l}$. These studies give rise to a concern that the preservation mechanism used in the EPA-approved methods may not be effective in preventing continued formation of HAAs during sample storage.

This paper describes research that was conducted to investigate the potential for continued HAA formation resulting from sample preservation and storage. It also describes microbiological preservation studies that we conducted to investigate the antimicrobial activity of samples collected and preserved in this manner. These studies validate the sample preservation techniques used in the currently approved methods for HAAs, and form the technical basis for the sample holding times established in EPA Method 552.3, which will be published in 2003.

\section{Materials and methods}

\subsection{Reagents and standards}

The haloacetic acids were obtained as solutions in methyl tertiary-butyl ether (MTBE) from Supelco in both their free acid form and as methyl esters, either as single-component mixtures or six-component mixtures $(97+\%)$. The internal standard (1,2,3-trichloropropane, $99 \%$ ) and the tested surrogates (2-bromo-2-methylpropanoic acid, 98\%; 2-bromopropanoic acid, $99+\%$; and 2,3-dibromopropanoic acid, 98\%) were obtained as neat materials from Aldrich. The surrogate methyl esters were obtained as neat materials from Fluka (2-bromo-2methylpropanoic acid, methyl ester, 99\%) or as solutions in MTBE (2-bromopropanoic acid, methyl ester, and 2,3-dibromopropanoic acid, methyl ester) from Supelco.

MTBE was obtained from Burdick \& Jackson (high purity). Methanol was obtained from either Burdick \& Jackson (purge-and-trap grade) or Fisher Scientific (optima grade). Sodium sulfate, copper sulfate pentahydrate, sulfuric acid, sodium bicarbonate, and ammonium chloride, all ACS grade, were obtained from Fisher Scientific. Reagent water was obtained using a Millipore MilliQ Plus TOC system. The growth media for the heterotrophic plate studies was R2A Agar (Difco Laboratories, Detroit, MI).

Helium (or Hydrogen), 99.999\% pure or better, was used as the GC carrier gas. Argon (95\%)/Methane (5\%) or nitrogen, $99.999 \%$ pure or better, were used as the ECD make-up gas.

\subsection{Analytical procedure}

Samples were extracted and analyzed for HAAs according to EPA Method 552.2 [4] using an Agilent 
Model 6890 gas chromatograph equipped with an electron capture detector and a Series 7683 injector (Agilent, Wilmington, DE). Separation was achieved on a J\&W DB-1701 capillary column $(30 \mathrm{~m} \times 0.25 \mathrm{~mm}$ i.d., $0.25 \mu \mathrm{m}$ film thickness) (Agilent Technologies, Wilmington, DE).

Heterotrophic plate count (HPC) analyses were performed using Standard Method 9215A and B protocols [15]. Pour plate studies of antimicrobial compounds were performed on R2A Agar inoculated with $0.20 \mathrm{ml}$ of sample, incubated at $35^{\circ} \mathrm{C}$. Colonyforming units (CFUs) were counted 5 days after inoculation.

The TOC concentrations were determined using Standard Method 5310C [15] on a Sievers Model 800 TOC Analyzer (Ionics, Boulder, CO). Free and total chlorine concentrations were determined using a DPDbased colorimetric test kit for free available chlorine (Hach Company, Loveland, CO).

\subsection{Haloacetic acid formation study}

A surface water that had been treated by coagulation, sedimentation and filtration (but not disinfection) was obtained from a local drinking water utility. A 4-1 aliquot of the water was fortified with $800 \mu$ l of bleach to yield a final free chlorine concentration of $6.0 \mathrm{mg} / \mathrm{l}$. This chlorinated water was divided into two, $2-1$ aliquots. To one aliquot, $200 \mathrm{mg}$ of ammonium chloride was immediately added to quench the free available chlorine simulating the sample collection protocol included in EPA-approved HAA analytical methods. Each of the two solutions was further divided into five, $250-\mathrm{ml}$ amber bottles. Triplicate solutions were extracted and analyzed for HAAs for each set of solutions each day during the sample storage study. Day 0 samples were analyzed immediately following preparation. All other samples were stored at $10^{\circ} \mathrm{C}$ for the first $48 \mathrm{~h}$, and then at $6^{\circ} \mathrm{C}$ for the remaining 28 days of the study. The initial temperature of $10^{\circ} \mathrm{C}$ has been published in recent EPA methods to allow samples to be shipped in containers cooled using chemical freezer packs rather than ice.

\subsection{Microbiological preservation studies}

Approximately eight liters of tap water was obtained from a surface water utility that disinfects with chlorine. The drinking water had a free available chlorine concentration of $1.0 \mathrm{mg} / \mathrm{l}$. The water was divided into five aliquots (A-E) and prepared as shown in Table 1. The free chlorine residual was quenched using ammonium chloride in three of the aliquots $(\mathrm{A}, \mathrm{B}$, and $\mathrm{C})$ and using sodium thiosulfate in the remaining two aliquots (D and E). Since disinfected drinking water samples have very small initial microbial populations, a $2.5-\mathrm{ml}$ aliquot of raw water containing indigenous microorganisms was added to two of the quenched tap water aliquots (one quenched with ammonium chloride [A] and one with sodium thiosulfate [D]). The volume of added raw water was chosen to give an HPC of between 50 and 200 colonies per plate for control samples. Four of the aliquots (A, B, D, and E) were then fortified with $10 \mu \mathrm{g} / \mathrm{l}$ of each of the nine HAAs. The fifth aliquot (quenched with ammonium chloride and no biological seed $[\mathrm{C}]$ ) was used to determine the background concentrations of the HAAs in the tap water over the storage study time frame.

Each of the five aliquots described above was poured into a series of $60-\mathrm{ml}$ amber bottles for storage. Day 0 samples were analyzed immediately following preparation. All other samples were stored at $10^{\circ} \mathrm{C}$ for the first $48 \mathrm{~h}$, and then at $6^{\circ} \mathrm{C}$ for the remaining 28 days of the study. Triplicate HAA analyses were performed on three bottles from each of the three sample sets quenched with ammonium chloride (A, B, and $\mathrm{C}$ ) beginning on day 0 and continuing at intervals over the course of the 28-day study. Triplicate HPC analyses were also conducted at the same time intervals on bottles from each of the four sample sets that were fortified with HAAs (A, B, D, and E).

\section{Results and discussion}

\subsection{Haloacetic acid formation study}

The current study was designed to investigate the potential for formation of HAAs during sample

Table 1

Preparation of samples for the microbiological preservation study

\begin{tabular}{llll}
\hline Sample & $\begin{array}{l}\text { Fortified concentration } \\
\text { for each HAA }\end{array}$ & Chlorine quenching reagent & Biological seed $^{\text {a }}$ \\
\hline A & $10 \mu \mathrm{g} / 1$ & Ammonium chloride $(100 \mathrm{mg} / \mathrm{l})$ & $2.5 \mathrm{ml} / 1$ \\
B & $10 \mu \mathrm{g} / 1$ & Ammonium chloride $(100 \mathrm{mg} / \mathrm{l})$ & None \\
C & None & Ammonium chloride $(100 \mathrm{mg} / \mathrm{l})$ & None \\
D & $10 \mu \mathrm{g} / 1$ & Sodium thiosulfate $(75 \mathrm{mg} / \mathrm{l})$ & $2.5 \mathrm{ml} / 1$ \\
E & $10 \mu \mathrm{g} / 1$ & Sodium thiosulfate $(75 \mathrm{mg} / \mathrm{l})$ & None \\
\hline
\end{tabular}

\footnotetext{
${ }^{\mathrm{a}}$ Raw water obtained from the Ohio River.
} 
preservation and storage. The rate of HAA formation is fastest when free chlorine first encounters TOC, and slows as both the free chlorine and the reactive portion of the TOC are consumed. A majority of the HAA formation is expected to be complete by the time compliance monitoring samples are collected in the distribution system. A set of experimental conditions was established that would challenge the effectiveness of using ammonium chloride to halt the formation of HAAs by using a freshly chlorinated sample in which HAA formation reactions should be occurring more quickly than normally observed in distribution system samples. The water used in the study had a TOC concentration of $3.9 \mathrm{mg} / \mathrm{l}$, which is above the median annual concentration observed in surface water sources sampled during the Information Collection Rule (ICR) [16] for water systems serving population of at least 100,000. These data are presented in Table 2. To further challenge the system, the water was chlorinated at a level that resulted in an initial free available chlorine level of $6.0 \mathrm{mg} / \mathrm{l}$, which is higher than $90 \%$ of the free chlorine residuals measured in the water entering the distribution systems sampled during the ICR (see Table 2). A summary of the procedure used to prepare, store and analyze these samples is described in Section 2.3.

Data from this storage study are presented in Figs. 1 and 2. In Fig. 1, the total haloacetic acid concentrations for the sum of the five regulated acetic acids, denoted as

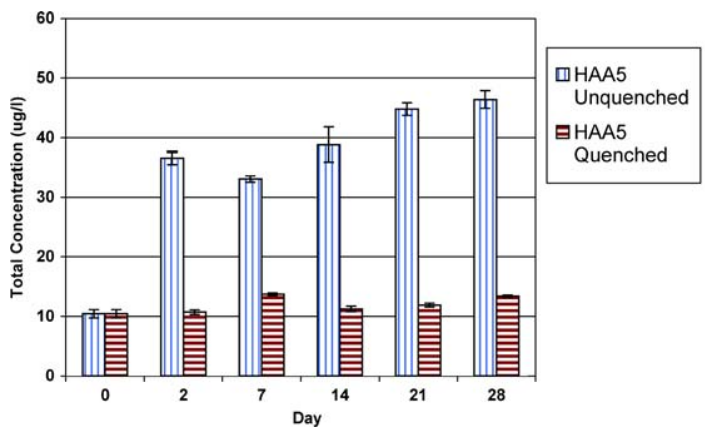

Fig. 1. Formation of the five regulated HAAs in an in-process water with a TOC of $3.9 \mathrm{mg} / 1$ and an initial free available chlorine level above $5 \mathrm{mg} / \mathrm{l}$ with, and without, ammonium chloride quenching. Error bars indicate \pm one standard deviation.

Table 2

TOC, free chlorine and total chlorine concentrations measured during the ICR in drinking waters systems serving at least 100,000 persons

TOC Concentrations in source water (annual average for each drinking water plant)

\begin{tabular}{lccccc}
\hline Water source & Number of plants & Mean $(\mathrm{mg} / \mathrm{l})$ & Median $(\mathrm{mg} / \mathrm{l})$ & 90th Percentile $(\mathrm{mg} / \mathrm{l})$ & $\mathrm{Range}(\mathrm{mg} / \mathrm{l})$ \\
\hline Surface & 294 & 3.15 & 2.71 & 5.28 & $<0.7-21.4$ \\
Ground & 102 & 1.47 & $<0.7$ & 3.33 & $<0.7-16.1$
\end{tabular}

Free chlorine concentrations in finished drinking water

\begin{tabular}{lccccc}
\hline Water source & Number of samples & Mean $(\mathrm{mg} / \mathrm{l})$ & Median $(\mathrm{mg} / \mathrm{l})$ & 90th Percentile $(\mathrm{mg} / \mathrm{l})$ & $\mathrm{Range}(\mathrm{mg} / \mathrm{l})$ \\
\hline Surface & 3409 & 1.2 & 1.1 & 2.1 & $0-12$ \\
Ground & 586 & 1.0 & 1.0 & 2.0 & $0-3.0$
\end{tabular}

Total chlorine concentrations in finished drinking water from chloraminated systems

\begin{tabular}{lccccc}
\hline Water source & Number of samples & Mean $(\mathrm{mg} / \mathrm{l})$ & Median $(\mathrm{mg} / \mathrm{l})$ & 90th Percentile $(\mathrm{mg} / \mathrm{l})$ & Range $(\mathrm{mg} / \mathrm{l})$ \\
\hline Surface & 1635 & 2.6 & 2.5 & 3.7 & $0.1-7.2$ \\
Ground & 267 & 3.0 & 3.0 & 4.5 & $0.2-5.0$
\end{tabular}

HAA5 concentrations in drinking water from surface water sources

\begin{tabular}{llllll}
\hline Water sample type & Number of samples & Mean $(\mu \mathrm{g} / \mathrm{l})$ & Median $(\mu \mathrm{g} / \mathrm{l})$ & 90 th Percentile $(\mu \mathrm{g} / \mathrm{l})$ & Range $(\mu \mathrm{g} / \mathrm{l})$ \\
\hline Finished & 1741 & 24 & 20 & 47 & $0-245$ \\
DS average $^{\mathrm{a}}$ & 1545 & 29 & 24 & 55 & $0-190$ \\
DS high $^{\mathrm{b}}$ & 1545 & 35 & 29 & 65 & $0-280$ \\
\hline
\end{tabular}

\footnotetext{
${ }^{a}$ Each data point represents the average HAA5 concentration from four samples collected on the same date within the distribution system

${ }^{\mathrm{b}}$ Each data point represents the highest HAA5 concentration measured in each four sample set collected on the same date within the distribution system.
} 
HAA5, are presented. Under the Stage 1 D/DBP Rule, the running annual average for any distribution system must not exceed $60 \mu \mathrm{g} / 1$ for HAA5. This group of HAAs includes monochloroacetic acid (MCAA), dichloroacetic acid (DCAA), trichloroacetic acid (TCAA), monobromoacetic acid (MBAA), and dibromoacetic acid (DBAA). Fig. 2 includes the sum of all nine haloacetic acids, denoted as HAA9. The four additional HAAs in this group are bromochloroacetic acid (BCAA), bromodichloroacetic acid (BDCAA), chlorodibromoacetic acid (CDBAA), and tribromoacetic acid (TBAA).

The figures show that the ammonium chloride was effective in halting most of the HAA formation. Over the 28-day period, the HAA5 concentration increased from 10 to $46 \mu \mathrm{g} / \mathrm{l}$ in the water containing a free chlorine residual. However, the HAA5 concentration only increased by $3 \mu \mathrm{g} / 1$ in the ammonium chloride-quenched water. A similar trend was shown for HAA9 with the concentration in the ammonium chloride-quenched water only increasing by $5 \mu \mathrm{g} / 1$ and the concentration in the water with the free chlorine residual increasing by

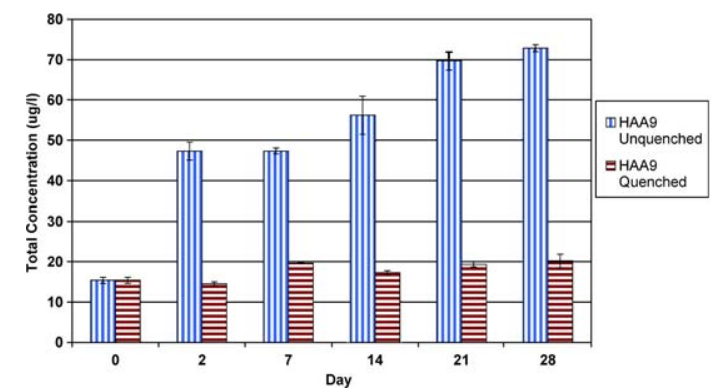

Fig. 2. Formation of all nine HAAs in an in-process river water with a TOC of $3.9 \mathrm{mg} / \mathrm{l}$ and an initial free available chlorine level above $5 \mathrm{mg} / \mathrm{l}$ with, and without, ammonium chloride quenching. Error bars indicate \pm one standard deviation.
$58 \mu \mathrm{g} / \mathrm{l}$. Average amounts for all nine HAA compounds are reported in Tables 3 and 4 for the chlorinated and ammonium chloride-quenched samples, respectively. Also included in the tables are results for the free available chlorine and total chlorine concentrations measured each day of the study, and the $\mathrm{pH}$ of each sample set. The data show that the $5 \mu \mathrm{g} / 1$ increase in HAA9 concentration in the ammonium chloride quenched water over the 28-day study period was primarily due to formation of small amounts $(4 \mu \mathrm{g} / \mathrm{l})$ of DCAA. For the same water, the concentration of DBAA increased by $0.7 \mu \mathrm{g} / 1$, BCAA increased by $1.7 \mu \mathrm{g} / 1$ and the MCAA concentration fluctuated during the 28 days with the net result being a $1.5 \mu \mathrm{g} / 1$ decrease. Over the storage period, the samples with a free chlorine residual showed concentration increases for the six HAAs (MCAA, DCAA, TCAA, DBAA, BCAA, and BDCAA) that were initially present. In general, the largest increases in individual HAA concentrations occurred between day 0 and day 2 for the quenched water.

The observation that only dihaloacetic acids (DCAA, DBAA, and BCAA) are formed in the presence of chloramines is consistent with the literature $[12,13]$. However, it is difficult to make direct comparisons between the amounts reported in previous studies and in this study, because the reaction conditions are different. The previous studies were designed to study HAA formation under potential water treatment conditions while this study focused on sample storage conditions. Diehl et al. [12] noted in their studies that HAA formation decreased as the chlorine-to-nitrogen ratio decreased. The current study used a large excess of ammonium chloride to quench the free chlorine residual which effectively dropped the chorine-to-nitrogen ratio to a much lower value than the previous studies $[12,13]$ and thus would be expected to reduce HAA formation.

Table 3

Average values for HAA formation in an in-process water (TOC $3.9 \mathrm{mg} / \mathrm{l}$ ) with a relatively high level of free available chlorine over 28 days.

\begin{tabular}{|c|c|c|c|c|c|c|c|c|c|c|c|c|}
\hline \multirow[t]{2}{*}{ Compound } & \multicolumn{2}{|l|}{ Day 0} & \multicolumn{2}{|c|}{ Day 2} & \multicolumn{2}{|l|}{ Day 7} & \multicolumn{2}{|c|}{ Day 14} & \multicolumn{2}{|c|}{ Day 21} & \multicolumn{2}{|c|}{ Day 28} \\
\hline & $\mu \mathrm{g} / 1$ & $\%$ RSD & $\mu \mathrm{g} / 1$ & $\%$ RSD & $\mu \mathrm{g} / 1$ & $\%$ RSD & $\mu \mathrm{g} / 1$ & $\%$ RSD & $\mu \mathrm{g} / 1$ & $\%$ RSD & $\mu \mathrm{g} / 1$ & $\%$ RSD \\
\hline MCAA & 2.5 & 26 & 2.1 & 18 & 1.4 & 8.7 & 1.8 & 9.4 & 2.6 & 25 & 3.3 & 21 \\
\hline MBAA & $<0.2$ & $\mathrm{nc}$ & $<0.2$ & $\mathrm{nc}$ & $<0.2$ & nc & $<0.2$ & $\mathrm{nc}$ & $<0.2$ & $\mathrm{nc}$ & $<0.2$ & $\mathrm{nc}$ \\
\hline DCAA & 3.8 & 0.9 & 20 & 1.9 & 17 & 1.5 & 21 & 6.5 & 24 & 2.7 & 26 & 2.4 \\
\hline TCAA & 2.8 & 1.1 & 11 & 7.0 & 11 & 3.0 & 13 & 9.9 & 15 & 2.0 & 14 & 2.1 \\
\hline DBAA & 1.3 & 3.9 & 3.8 & 8.3 & 3.1 & 3.7 & 3.3 & 9.1 & 3.5 & 2.5 & 3.6 & 2.5 \\
\hline BCAA & 2.8 & 2.0 & 8.0 & 10 & 8.9 & 2.6 & 9.8 & 9.1 & 11 & 3.4 & 11 & 1.1 \\
\hline BDCAA & 2.2 & 3.2 & 2.8 & 13 & 5.0 & 7.8 & 7.6 & 12 & 14 & 6.6 & 15 & 4.4 \\
\hline CDBAA & $<0.2$ & $\mathrm{nc}$ & $<0.2$ & $\mathrm{nc}$ & $<0.2$ & $\mathrm{nc}$ & $<0.2$ & $\mathrm{nc}$ & $<0.2$ & nc & $<0.2$ & $\mathrm{nc}$ \\
\hline TBAA & $<0.2$ & $\mathrm{nc}$ & $<0.2$ & $\mathrm{nc}$ & $<0.2$ & $\mathrm{nc}$ & $<0.2$ & nc & $<0.2$ & nc & $<0.2$ & $\mathrm{nc}$ \\
\hline Free available chlorine & \multicolumn{2}{|c|}{$5.5 \mathrm{mg} / 1$} & \multicolumn{2}{|c|}{$5.3 \mathrm{mg} / 1$} & \multicolumn{2}{|c|}{$4.3 \mathrm{mg} / 1$} & \multicolumn{2}{|c|}{$3.5 \mathrm{mg} / 1$} & \multicolumn{2}{|c|}{$3.8 \mathrm{mg} / 1$} & \multicolumn{2}{|c|}{$3.5 \mathrm{mg} / 1$} \\
\hline
\end{tabular}

$\mathrm{pH}=7.84$, no ammonium chloride, $\mathrm{nc}=$ not calculated. 
Table 4

Average values for HAA formation in the same in-process water reported in Table 3, but quenched with $100 \mathrm{mg} / \mathrm{lammonium}$ chloride

\begin{tabular}{|c|c|c|c|c|c|c|c|c|c|c|c|c|}
\hline \multirow[t]{2}{*}{ Compound } & \multicolumn{2}{|c|}{ Day 0} & \multicolumn{2}{|c|}{ Day 2} & \multicolumn{2}{|c|}{ Day 7} & \multicolumn{2}{|c|}{ Day 14} & \multicolumn{2}{|c|}{ Day 21} & \multicolumn{2}{|c|}{ Day 28} \\
\hline & $\mu \mathrm{g} / 1$ & $\%$ RSD & $\mu \mathrm{g} / 1$ & $\%$ RSD & $\mu \mathrm{g} / 1$ & $\%$ RSD & $\mu \mathrm{g} / 1$ & $\%$ RSD & $\mu \mathrm{g} / 1$ & $\%$ RSD & $\mu \mathrm{g} / 1$ & $\%$ RSD \\
\hline MCAA & 2.5 & 26 & $<0.4$ & $\mathrm{nc}$ & 3.9 & 5.4 & 0.42 & 15 & 0.59 & 8.7 & 0.97 & 13 \\
\hline MBAA & $<0.2$ & $\mathrm{nc}$ & $<0.2$ & $\mathrm{nc}$ & $<0.2$ & $\mathrm{nc}$ & $<0.2$ & $\mathrm{nc}$ & $<0.2$ & $\mathrm{nc}$ & $<0.2$ & $\mathrm{nc}$ \\
\hline DCAA & 3.8 & 0.9 & 6.0 & 10 & 5.6 & 0.7 & 6.4 & 3.5 & 7.1 & 3.8 & 7.7 & 1.0 \\
\hline TCAA & 2.8 & 1.1 & 3.2 & 6.0 & 2.6 & 2.1 & 2.7 & 5.6 & 2.5 & 3.0 & 2.7 & 5.8 \\
\hline DBAA & 1.3 & 3.9 & 1.6 & 5.8 & 1.6 & 1.2 & 1.8 & 3.7 & 1.8 & 3.0 & 2.0 & 2.9 \\
\hline BCAA & 2.8 & 2.0 & 2.5 & 17 & 3.5 & 1.0 & 3.6 & 2.9 & 4.0 & 3.1 & 4.5 & 3.3 \\
\hline BDCAA & 2.2 & 3.2 & 1.4 & 21 & 2.5 & 1.8 & 2.2 & 14 & 3.5 & 9.2 & 2.4 & 58 \\
\hline CDBAA & $<0.2$ & $\mathrm{nc}$ & $<0.2$ & $\mathrm{nc}$ & $<0.2$ & $\mathrm{nc}$ & $<0.2$ & $\mathrm{nc}$ & $<0.2$ & $\mathrm{nc}$ & $<0.2$ & $\mathrm{nc}$ \\
\hline TBAA & $<0.2$ & $\mathrm{nc}$ & $<0.2$ & $\mathrm{nc}$ & $<0.2$ & $\mathrm{nc}$ & $<0.2$ & $\mathrm{nc}$ & $<0.2$ & $\mathrm{nc}$ & $<0.2$ & nc \\
\hline Total chlorine & \multicolumn{2}{|c|}{$6.0 \mathrm{mg} / 1$} & \multicolumn{2}{|c|}{$6.0 \mathrm{mg} / 1$} & \multicolumn{2}{|c|}{$5.5 \mathrm{mg} / 1$} & \multicolumn{2}{|c|}{$5.5 \mathrm{mg} / 1$} & \multicolumn{2}{|c|}{$6.2 \mathrm{mg} / \mathrm{l}$} & \multicolumn{2}{|c|}{$6.0 \mathrm{mg} / 1$} \\
\hline
\end{tabular}

$\mathrm{pH}=8.10, \mathrm{nc}=$ not calculated.

\subsection{Microbiological preservation studies}

The preservation of organic contaminants in water samples from microbiological degradation is a complex issue that requires careful consideration [17]. The purpose of this study was not to design a new preservation protocol for HAAs, but rather to evaluate if the chloramines formed during sample dechlorination served as a microbiological preservative under sample collection and storage conditions.

Samples A, B, and C in the microbiological preservation studies were analyzed for HAAs on days $0,3,7,14$, 21 , and 28 in order to evaluate the stability of these compounds in water containing a moderate combined chlorine residual. The HAA concentrations did not change significantly in any of the samples over the course of the study. The results for Sample A that was fortified with both HAAs and a biological seed are shown in Fig. 3 as percent recovery relative to the fortified concentration corrected for the background HAA levels present in the unfortified sample (C) analyzed at the same time.

Even though acclimated microbes can readily degrade HAAs [9-11], it was not envisioned that the general microbial population used in this study would degrade these targets. The antimicrobial effectiveness of the chloramines formed during sample quenching was evaluated by comparing the CFUs observed in the samples containing a combined chlorine residual (A and B) to the samples that did not contain a chlorine residual as a result of being quenched with sodium thiosulfate (D and E). Data from the pour plate studies are presented in Fig. 4. Combined chlorine values measured during the 28-day period for the ammonium chloride quenched waters remained near $0.8 \mathrm{mg} / \mathrm{l}$. Both sets of the ammonium chloride-quenched samples (A and B) demonstrated effective antimicrobial activity (CFU/ml values near zero throughout the study), while the

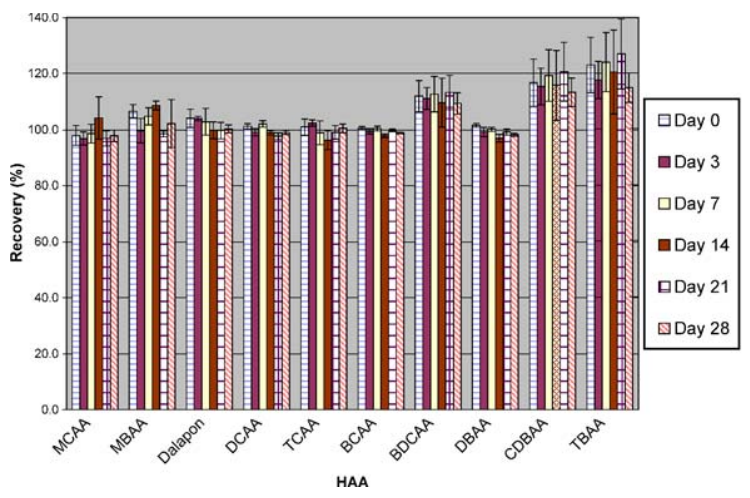

Fig. 3. Storage stability over 28 days for HAAs prepared as described in Table 1, Sample A and then stored according to EPA method protocols. Error bars indicate \pm one standard deviation.

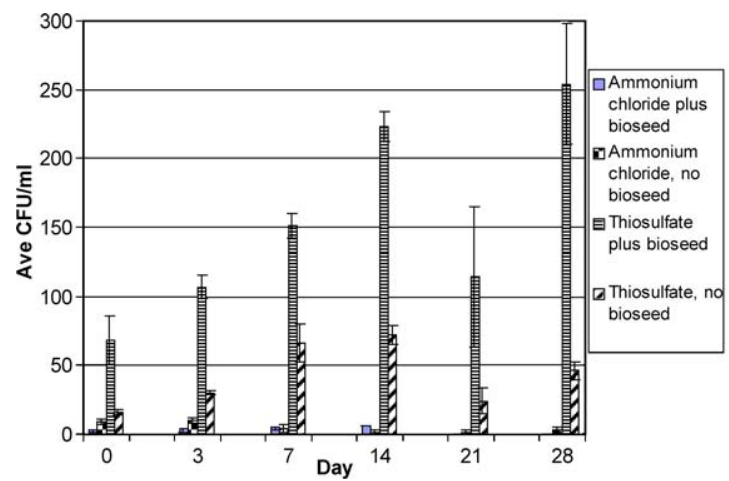

Fig. 4. Heterotrophic plate count studies conducted during the 28-day microbiological preservation studies to determine the antimicrobial effectiveness of the chloramine residual formed as a result of sample quenching. Error bars indicate \pm one standard deviation. 
samples dechlorinated with thiosulfate (D and E) did not.

\section{Conclusions}

Work reported in the literature, which indicated that HAAs can be formed during chloramination, led to concern over the mechanism used to quench the free chlorine residual in drinking water samples in the EPA-approved monitoring methods for HAAs. Our studies did find some evidence for the production of dihaloacetic acids. However, the amount formed in the quenched samples was minimal in comparison to the amount formed in the samples containing a free chlorine residual. It is also important to note that the effectiveness of adding ammonium chloride to convert free chlorine to chloramines in order to halt HAA formation was tested in a water that was freshly chlorinated and thus would be comparable to samples collected at a water treatment plant immediately after the application of chlorine. The test conditions were more challenging than those expected for typical compliance monitoring samples. In addition, the chlorine dose was higher than typically used during water treatment. Compliance monitoring samples are collected in the distribution system after the water has been in contact with chlorine for a period of time. The rate of HAA formation decreases over time as the most reactive TOC is consumed, so distribution system samples would not be expected to exhibit as much HAA formation as a freshly chlorinated water.

The HAA5 formation in the unquenched sample was greater than the median HAA5 concentrations measured in distribution systems during the ICR (see Table 2). After storage at two days under refrigerated conditions, the HAA5 concentration was $37 \mu \mathrm{g} / 1$ in the unquenched sample. This indicates the water selected for the study contained enough reactive organic material to produce HAA5 concentrations similar to those observed in drinking water distribution systems and thus provided a realistic challenge for demonstrating that formation reactions can be halted.

The microbiological preservation studies indicated that HAAs are stable in ammonium chloride-quenched waters with a combined chlorine disinfectant residual under sample storage conditions over 28 days. In addition, water that contains modest combined chlorine levels inhibits the growth of microorganisms during sample storage. These data do not, however, support extending the sample hold time to 28 days as this would require a persistent disinfectant over this time period and this condition can not be assured for all water types.

The data presented herein warranted the inclusion of ammonium chloride as the chlorine quenching reagent for the EPA Method 552.3 and strongly support the use of ammonium chloride in the currently approved methods. The data also indicate that ammonium chloride may not instantaneously halt all HAA formation reactions, and thus highly reactive samples like those collected for process monitoring may require additional handling procedures to obtain the most accurate data. In addition, the data suggest that samples containing a combined chlorine residual should be protected from microbial degradation of the HAAs, because the residual inhibits microbial growth.

\section{Acknowledgements}

All work was performed at the EPA Office of Ground Water and Drinking Water Technical Support Center Laboratory located in Cincinnati, Ohio. This work has been funded wholly or in part by the United States Environmental Protection Agency under contracts (Contract Numbers: 68-C6-0040 and 68-C-01-098) to Shaw Environmental, Inc. It has been subject to the Agency's review, and it has been approved for publication as an EPA document. Mention of trade names or commercial products does not constitute endorsement or recommendation for use.

The authors would like to thank Ms. Judy Suzurakawa from the Cincinnati Waterworks Laboratory for supplying in-process water for these studies.

\section{References}

[1] EPA Integrated Risk Information System, www.epa.gov/ iris/dindy/0654.html.

[2] Environmental Protection Agency, Disinfectants and Disinfection Byproducts; National Primary Drinking Water Regulations: Final Rule, Federal Register, December 16, vol. 63, No. 241, 1998. p. 69390-476.

[3] Hodgeson JW, Becker D. EPA Method 552.1, Determination of haloacetic acids and dalapon in drinking water by ion-exchange liquid-solid extraction and gas chromatography with electron capture detection. Rev. 1.0, Methods for the determination of organic compounds in drinking water, Supplement II, EPA/600/R-92/129, US EPA, Office of Research and Development, Washington, DC, 1992.

[4] Munch DJ, Munch JW, Pawlecki AM. EPA Method 552.2, Determination of haloacetic acids and dalapon in drinking water by liquid-liquid extraction, derivatization and gas chromatography with electron capture detection. Rev. 1.0, Methods for the determination of organic compounds in drinking water, Supplement III, EPA/600/ R-95/131, US EPA, Office of Research and Development, Washington, DC, 1995.

[5] Standard Method 6251B. Disinfection by-products: haloacetic acids and trichlorophenol, micro liquid-liquid extraction GC method. In: Eaton AD, Clesceri LS, Greenburg AE, editors. Standard methods for the examination of 
water and wastewater (19th ed.), American Public Health Association, Washington DC, 1995.

[6] Fuast DF, Osman MA. Chemistry of Water Treatment. Woburn, MA: Butterworth Publishers; 1983. p. 616-32.

[7] Bassett MV, Wendelken SC, Dattilio TA, Pepich BV, Munch DJ. The application of tris buffer and copper sulfate for the preservation of phenylurea pesticides analyzed using US EPA Method 532 in the UCMR survey. Environ Sci Technol 2002;36:1809-14.

[8] Krasner SW, Sclimenti MJ, Hwang CJ. Experiences with implementing a laboratory program to sample and analyze for disinfection by-products in a national study. In: Disinfection by-products: current perspectives. Denver, CO: AWWA; 1989. p. 129-69.

[9] Williams SL, Rindfleisch DF, Williams RL. Deadend on haloacetic acids. Proceedings of the 1994 WQTC, San Francisco, CA, Nov. 6-10, Denver, CO: AWWA; 1994. p. 1053-65.

[10] Williams SL, Williams RL, Gordon AS. The impact of bacterial degradation of haloacetic acids in the distribution system. Proceedings of the 1996 WQTC, Boston, MA, Nov. 17, Denver, CO: AWWA; 1996.

[11] Williams SL, Williams RL, Yuan J. Bacterial degradation of haloacetic acids in the distribution system. Proceedings of the 1998 WQTC, San Diego, CA, Nov. 1, Denver, CO: AWWA; 1998.

[12] Diehl AC, Speitel Jr. GE, Symons JM, Krasner SW, Hwang CJ, Barrett SE. DBP Formation During Chloramination. J AWWA 2000;92(6):76-90.

[13] Cowman GA, Singer PC. Effect of bromide ion on haloacetic acid speciation resulting from chlorination and chloramination of aquatic humic substances. Environ Sci Technol 1996;30(1):16-24.

[14] Richardson SD, Thurston AD, Caughran TV, Chen PH, Collette TW, Floyd TL, Schenck KM, Lykins BW, Sun G, Majetich G. Identification of new ozone disinfection byproducts in drinking water. Environ Sci Technol 1999;33(19):3368-77.

[15] Standard Methods 9215A, 9215B and. In: Eaton AD, Clesceri LS, Greenberg AE, editors. Standard methods for the examination of water and wastewater (19th ed.). Washington, DC: American Public Health Association; 1995.

[16] Environmental Protection Agency. ICR Auxiliary 1 Database, Version 5.0. EPA 815-C-00-002, Office of Water, Washington, DC, 2000.

[17] Winslow SD, Pepich BV, Bassett MV, Wendelken SC, Munch DJ, Sinclair JL. Microbial inhibitors for US EPA drinking water methods for the determination of organic compounds. Environ Sci Technol 2001;35:4103-10. 